\title{
Causes of Stress Before, During and After Organizational Change: A Qualitative Study
}

Roy K. Smollan

Journal of Organisational Change Management, 28(2), 301-314.

\begin{abstract}
Purpose - Since prior empirical research has seldom compared causes of stress before, during and after organizational change this study sought to identify stressors as change unfolded over time and to identify what led to variations in stress levels.
\end{abstract}

Design/methodology/approach - Semi-structured interviews were conducted in 2012 with 31 staff in a range of clinical and non-clinical positions in a New Zealand public health organization that had experienced considerable change.

Findings - For most respondents the transition phase was the most stressful as it created job insecurity and was handled with insufficient information, consultation and support and for the balance stress increased after the change, which created additional demands that usually needed to be met with fewer resources. The stress of others emerged as a new category of stressor during the transition stage.

Research limitations/implications - Memories fade and the lines between stages of change are often blurred with one change sometimes occur simultaneously with another or following it. Further studies, quantitative and qualitative, could explore stressors at different points in time, in different national contexts and in private and public organizations.

Practical implications - Leaders of public sector organizations need to be mindful of the deleterious effects of stress from organizational change and create cultures, strategies and practices that mitigate the stress.

Originality/value - This is apparently the first qualitative study that traces the causes of stress as organizational change moves through various phases.

Key words Occupational stress, Organizational change, Public sector, Qualitative research 


\section{Paper type Research paper}

In their introduction to a recent book Oreg et al. (2013) assert that too little literature on organizational change is devoted to individual psychological reactions. This is a cause for concern given that studies indicate that change is often stressful (e.g. Fugate et al., 2012; Lawrence and Callan, 2011). This is partly due to the anticipated or actual negative outcomes of the change, such as job losses or reduced autonomy, and partly due to the process of transition which may create extra work and produce considerable uncertainty and anxiety. On the other hand, the assumption that change will be stressful, and this is not always accurate, tends to overlook two issues: firstly, some degree of stress is present in any job at any time and secondly, while some changes increase stress, others may reduce it (Karasek, 2004) or have little impact on it. Many previous studies have explored stress during and after change but there appear to be few that also include an analysis of the stress that predated the change (see Paulsen et al., 2005, for an exception).

The main purposes of this paper are therefore to address two gaps in the empirical literature, an analysis of the causes of stress before, during and after an organizational change and of what led to these variations in stress levels, and to add to the thin qualitative literature on stressful change in the public sector. Organizations of this type are at times faced with issues more complex than those faced by commercial organizations when they move to what has been termed New Public Management (Diefenbach, 2009; Kuipers et al., 2013; Noblet et al., 2006). This emphasizes cost-cutting, key performance indicators, efficiency and accountability and often subjects organizational members to acute levels of stress. Addressing these research questions should contribute to a better theoretical understanding of stressful change and aid public sector leaders in mitigating its more harmful effects.

\section{Literature review}

Causes of occupational stress 
According to Lazarus (1993) stress emanates from perceptions of harm, threat or challenge in a person's environment. It is a negative psychological and physiological condition that derives from a combination of forces internal and external to the individual that tax a person's coping ability. Hobfoll's (1998) Conservation of Resources Theory proposes that the experienced or anticipated loss of tangible, social and psychological resources is the dominant source of stress. The Demand Control Support model (Karasek et al., 1998) identifies high job demands and low control as significant sources of stress. In their Job Demands-Resources model Bakker and Demerouti (2007) propose a more complex set of dynamics whereby high job demands (mental, emotional and physical) coupled with low resources (such as poor supervisory support and little feedback) lead to strain and demotivation.

In work contexts a number of instruments have categorized sources of stress. Karasek et al. (1998) focus on five key groups: psychological demands, lack of decision latitude, lack of social support, physical demands and job insecurity. Maslach and Leiter (2008) identify six major sources of burnout: workload, lack of control, low reward, inadequate community/social factors), unfairness and inappropriate values. The ASSET instrument (Faragher et al., 2004) contains seven categories: work relationships, work-life balance, overload, job security, control, resources and communication, pay and benefits.

Many of these causes of stress are exacerbated by organizational change but it is interesting that none of the sources cited above actually list organizational change as a stressor. However, in an undated leaflet (p. 3), the United Kingdom government authority, the Health and Safety Executive, lists “change and how it’s managed” as a source of occupational stress, together with relationships, job demands, the nature of the role, lack of control and support.

Stress during different phases of organizational change 
Isabella (1990) explored the cognitive responses of managers to the different phases of one change which she labelled as anticipation, confirmation, culmination (the implementation stage) and aftermath. Different concerns emerged, such as increased workload and loss of status and benefits, as new information was received and actions were taken. Some researchers maintain that the transition phase is more stressful than the aftermath, given the uncertainty and disruption that occurs in designing and implementing change (Bridges, 2003). In their metaanalysis Bamberger et al. (2012) found in 11 out of 17 studies that most mental health problems arose from this phase. However, the boundaries between phases of many change initiatives are blurred, given that rumours often emerge before formal announcements, and that parts of the transition phase can been perceived as the beginning of the aftermath.

\section{Quantitative studies of the causes of stress from organizational change}

The nature of a job is a prime potential source of strain and Karasek et al. (1998) measure one element, psychological demands, by including items on workload, the speed of work, concentration and role ambiguity. Many change initiatives affect these factors since they are intentionally directed at achieving productivity gains through freezes on hiring, layoffs or other forms of cost control. In an analysis of empirical research into the prevention of stress Karasek (2004) refers to 11 case studies where organizational change was the context. An increase in workload has been found to cause strain when it is anticipated or actually experienced, as Teo et al. (2012) found in their study of nurses. In the context of downsizing, a stressful experience for most organizational members, Armstrong-Stassen (2005) reported negative consequences for middle and senior managers in the public sector who suffered from higher workloads during the transition phase.

Studies of change in the public sector (e.g. Fugate et al., 2012; Mak and Mueller, 2000; Paulsen et al., 2005; Rafferty and Griffin, 2006), as they do elsewhere, reveal that uncertainty 
and in particular, job insecurity, are inherent features of many types of change. Outcomes can seldom be accurately predicted and strain pervades the early and middle stages of the process. In cases of downsizing the strain of uncertainty is a common outcome for survivors who think they may be next in line (Armstrong-Stassen, 2005; Mak and Mueller, 2000), and the strain of the victims is even greater when they discover they have lost their jobs (Parris and Vickers, 2010; Paulsen et al., 2005).

When organizational members believe they have little control over work outcomes, including change outcomes, strain develops, as surveys in public sector organizations have shown (e.g. Devine et al., 2003; Paulsen et al., 2005). This is partly because of potentially negative tangible outcomes, such as increased workload, inferior working conditions and layoffs, but also because of negative socio-emotional outcomes, such as lower status, lack of participation in decision-making and deficient organizational support (Noblet et al., 2006; Pick et al., 2012).

Poor relationships with organizational management and individual supervisors have been shown to contribute to stressful experiences in change contexts (Riolli and Savicki, 2006). Perceived lack of support during change is not only a stressor in itself but also undermines the ability of members to cope with the strain, as Lawrence and Callan (2011) and Teo et al. (2012) found in the public health sector. On an organizational level poor communication has led to greater strain (Riolli and Savicki, 2006), through heightened uncertainty (Paulsen et al., 2005), and perceptions of injustice (Fugate et al., 2012; Smollan, 2012).

\section{Qualitative studies of the causes of stress from organizational change}

While there have been far fewer qualitative studies they have presented searing individual accounts of the stressors of the processes and outcomes of change that quantitative approaches are unable to produce. For example, participants have reported that "people were breaking down 
and crying” (Clair and Dufresne 2004, p. 1608); “a lot of guys that were about to retire got nothing...they were devastated... 6 employees committed suicide” (Driver 2009, p. 360); "We had this manager who would taunt us and say things like 'none of you will be here in a few months and your kids will be derelicts”” (Bryant 2006, p. 253); "We were demoralized...It was big brother stomping on little brother” (Smollan and Sayers, 2009, p. 445).

Many of the themes of quantitative studies have emerged in interviews where participants have revealed the complexity of change and the rise and fall in stress levels as it plays out. Robinson and Griffiths (2005) found five major sources of stress in employees of a government department undergoing major change: increased workload, ambiguity and uncertainty, interpersonal conflict, unfairness and loss (of expertise, relationships and selfesteem). Using interviews to supplement their quantitative analysis of change in the university sector, Pick et al. (2012) found that uncertainty, lack of participation and increased workloads were particularly stressful. Allen et al. (2007) reported that stress emanated from uncertainty regarding the organization's direction and the nature of the employee's future role. Through interviewing 180 managers and staff on change in the public and private sectors, individually or in groups, Saksvik et al. (2007) identified five categories of strain: awareness of organizational norms, understanding of diverse perceptions, early role clarification, managerial availability and constructive conflict management. A study of women in the public sector (Baltzer et al., 2011) revealed that the main sources of strain that led to greater sickness absence were lack of participation in change processes, unclear work tasks and the humiliation of powerlessness and low status. Bryant (2006) and Smollan (2012) found that various forms of injustice triggered powerful negative emotions during change.

Downsizing, a stressful experience for most of those involved, has highlighted a number of different causes for various types of actor. In a study of male managers who were victims of downsizing Parris and Vickers (2010) captured feelings of anger, sadness, fear and 
embarrassment. These accompanied perceptions characterized by the researchers as "failing as a breadwinner”, "being less of a person” and "losing success”. A study by Campbell-jamison et al. (2001) reported that survivors in a recently-privatized organization were angry and bitter at how managers had treated victims and themselves through poor communication, unclear selection procedures and lack of support. Survivors also experienced anxiety over the loss of colleagues and uncertainty about their own futures in the organization. A role not often researched is that of those who manage downsizing, who have termed themselves grim reapers (Clair and Dufresne, 2004) and executioners (Gandolfi, 2009). Respondents in these studies reported considerably high levels of guilt and anxiety in dealing with the stress of the victims.

Since extant research, both quantitative and qualitative, has seldom investigated causes of stress before, during and after organizational change a new research study was developed to answer the following research questions: What factors trigger stress at different phases of organizational change and how and why do they vary over time?

\section{Method}

The research site

Public healthcare in New Zealand is primarily offered though a number of agencies known since 2000 as District Health Boards (DHBs) (Gauld, 2003). Considerable change has taken place with a number of nation-wide strategic restructurings involving alterations to geographic boundaries, service provision and funding. Within each DHB changes have continued as a result of external and internal forces. Some functions, such as procurement, accounting and information technology, have been partly outsourced to an organization which is a joint venture between a number of the DHBs and a private sector company. In addition, some DHBs have recently agreed to share the provision of certain services with one manager and joint staff operating across two or more Boards. 


\section{Participants and procedure}

One DHB, which provides an extensive range of services from hospitals, clinics and specialist centres across a wide geographic area, allowed research access to a section of the workforce. Out of a staff of several thousand, a list of about 200 names and email addresses of those whose departments had recently been affected by change were provided by the Human Resources Department. They were invited by researcher email to volunteer for confidential interviews for a project titled The Stress of Organizational Change. In the beginning I interviewed all those who responded. As most of these were White women I later sent out another email to all the male names on the list and went through official DHB networks by telephone and email to solicit more ethnic minority representation.

In total 31 members of staff were interviewed in 2012 in their offices or onsite meeting rooms in sessions lasting 35 to 75 minutes. There were 25 female and six male participants, 20 White, three Maori, four Asian and three of Pacific Island background. Of these 12 worked in clinical roles, such as nursing and physiotherapy, some as team leaders who currently had no clinical duties. None were doctors, who, according to the HR contact, had not experienced much change. There were 19 in non-clinical roles such as information technology, training and accounting, some with qualifications and prior experience in clinical fields. Regarding hierarchical level, six were non-managerial employees, 15 were first-level managers or professional team leaders, eight were in middle management and two in senior management. The age range was 32 to 65 years (mean 40.3) and length of service varied from four to 27 years (mean 10.7).

In a semi-structured format the participants were first asked to explain what they meant by the term stress. They were then invited to describe sources of stress before a change, asked to outline a particular change they had experienced in the organization, comment on the causes 
of stress during the transition phase and finally consider the causes of stress after the change was in place, up to the present. They were also asked to comment how severe the stress was for themselves and others, what the consequences were and how much support they had received from various elements of the organization. If it was not clearly evident the respondents were asked which stage had been the most stressful. The interviews were recorded and softcopies of the verbatim transcripts were emailed to the participants for comments. To aid data analysis tables were drawn up of stressors before, during and after change. The common themes that emerged for each phase after several readings of the transcripts are reported below and selected quotes were chosen to highlight the issues.

\section{Findings and discussion}

Before the change

Many of the respondents identified major aspects of the wide-ranging restructuring programme that had begun several years before while others focussed on different types of change. Most initially reported that before the change in question their stress levels had been fairly low, with many referring to these as "normal” stresses and "part of the job”. On probing, however, aspects of their roles were revealed to have been more challenging at the time. Stressors included coming to grips with a new role and a new manager when appointed, expectations of others, heavy workloads, targets, deadlines, responsibilities, relationship issues (internal and external), insufficient resources (including staff), crises (particularly in clinical situations) and health issues (for themselves or their families). A few spoke of a previous change or constant change as an additional source of stress.

\begin{tabular}{|l|l|}
\hline Stressor & Sample quotes \\
\hline $\begin{array}{l}\text { Relationships: } \\
\text { external }\end{array}$ & $\begin{array}{l}\text { A newly diagnosed patient with cancer or any chronic illnesses can cause a lot of stress } \\
\text { on the family and patient and it can also rub off on us. } \\
\text { Family violence, neglect, child abuse, elderly abuse. }\end{array}$ \\
\hline $\begin{array}{l}\text { Relationships: } \\
\text { internal }\end{array}$ & $\begin{array}{l}\text { Sometimes people just working together in a close environment just don't get on [...] } \\
\text { people not pulling their weight [...] personality conflicts. }\end{array}$ \\
\hline
\end{tabular}




\begin{tabular}{|l|l|}
\hline $\begin{array}{l}\text { Limited } \\
\text { resources }\end{array}$ & $\begin{array}{l}\text { Downward pressure from the organization to save money. } \\
\text { Trying to maintain a good service with limited resources. } \\
\text { High levels of sick calls of staff [...] leaving patients compromised. }\end{array}$ \\
\hline Workload & $\begin{array}{l}\text { You get treated like you don't manage your case load properly. } \\
\text { The volume of work that I've got to do and not having enough time. }\end{array}$ \\
\hline Responsibility & $\begin{array}{l}\text { Situations where you have to make decisions where there is a high degree of } \\
\text { accountability and potential to get it wrong. }\end{array}$ \\
\hline
\end{tabular}

Table 1: Causes of stress before the change

The nature of these stressors, some of which are bound in the context of the organization and the New Zealand health sector, are nevertheless not dissimilar to what previous literature has revealed about occupational stress. The Demand-Control-Support Model (Karasek, 2004) identifies three stressors that manifested in the pre-change phase for respondents in the DHB: psychological demands (particularly job requirements and relationship management), lack of social support (from some managers and colleagues) and job insecurity (when a change elsewhere signalled the precariousness of their own tenure or status).

Lack of resources was a stressor for several respondents, which resulted in the frustration of being unable to do the best job possible, while staff shortages in particular increased their workload. Lack of resources is an essential element of Hobfoll's (1998) Bakker and Demerouti's (2007) models and has been found in various empirical studies to be a major source of stress (e.g. Faragher et al., 2004; Teo et al., 2012). Prior research into organizational stress has demonstrated the relevance of poor management and inadequate communication (Faragher et al., 2004; Riolli and Savicki, 2006), and in the current study these were severe sources for some respondents but much milder for others.

\section{During the change}

For many respondents stress levels rose considerably in the transition phase of a change, which was taken to commence when respondents first became aware of the change. Some had heard rumours of change from various quarters inside and outside the organization and some assumed 
that the major restructuring, announced by the CEO and later confirmed by his replacement, could sooner or later impact on their own roles. A recurring stressor revealed in the interviews was uncertainty as to how the respondents would be affected. While some were given precise indications that they were "in scope", a term commonly used, others complained that it was unclear for a considerable period whether they would be required to apply for new roles, be redeployed or simply be made redundant. Some were stressed that new job descriptions and person specifications were unclear and that remuneration for new roles had not yet been established. The deleterious effects of rumours and the uncertainty of how change would impact on roles and relationships in the DHB were similar to those reported in prior empirical studies (Fugate et al., 2012; Paulsen et al., 2004; Rafferty and Griffin, 2006).

\begin{tabular}{|l|l|}
\hline Stressor & Sample quotes \\
\hline Uncertainty & $\begin{array}{l}\text { You had no idea whether you were swimming inside the net or outside the net. } \\
\text { We were in limbo, expecting the axe to fall. } \\
\text { Everyone was fearful of losing their roles. }\end{array}$ \\
\hline $\begin{array}{l}\text { Unclear roles or } \\
\text { remuneration }\end{array}$ & $\begin{array}{l}\text { It was a brand new role that nobody had any idea what it entailed. } \\
\text { I wasn't privy to what the job descriptions were going to look like, what the ideas were } \\
\text { or how the department was going to look eventually. } \\
\text { I didn't actually know how much my salary level was going to be, until two days after } \\
\text { I'd applied for the job. }\end{array}$ \\
\hline $\begin{array}{l}\text { Lack of } \\
\text { consultation/ } \\
\text { participation }\end{array}$ & $\begin{array}{l}\text { It was done really badly in that there was no discussion, it was just dumped on us at a } \\
\text { meeting. } \\
\text { He swept in, passed us some envelopes and then he swept out again. }\end{array}$ \\
\hline $\begin{array}{l}\text { Relationships: } \\
\text { internal }\end{array}$ & $\begin{array}{l}\text { They've been taken on new managers because they've got a ruthless streak. } \\
\text { She was the worst manager I've ever reported to [...] a real ball-breaker. } \\
\text { They [senior management] chose to treat us as if we were stupid. } \\
\text { I received some hate mail [from lower level staff]. }\end{array}$ \\
\hline $\begin{array}{l}\text { The stress of } \\
\text { others }\end{array}$ & $\begin{array}{l}\text { What I found stressful was seeing the distress of the staff who had been informed that } \\
\text { they may lose their jobs. } \\
\text { I was worried for my two colleagues [...] that was probably the biggest stress for me } \\
\text { while the restructure was announced. }\end{array}$ \\
\hline
\end{tabular}

\section{Table 2: Causes of stress during the change}

Some respondents resented poor communication about the purpose of the change and the likely impact on them and their colleagues. While a few were pleased with the type of input they could give to change processes others were cynical and angry in believing that consultation 
was insincere and that management would do whatever they wanted, regardless of staff views. Some referred to the "usual HR process" that was designed to avoid grievances and legal action, while others, especially those who had previously enjoyed greater participation, felt particularly bitter because there had been little if any consultation. Riolli and Savicki (2006) demonstrated that procedural justice (such as managers spending time explaining change reasons and answering questions) produced considerably less strain in employees than those who had been given a perfunctory explanation. Similarly, Pick et al. (2012) found that inadequate information and exclusion from decision-making were resented by university staff.

Some respondents were very appreciative of the support they received from their managers or more senior management while others were distraught at the low level of support (even though employee assistance programmes are available in the organization). More acutely there were allegations of incompetent and insensitive management. Some of their managers had been made redundant or had resigned during the process and the respondents were unhappy that interim managers had seemed unconcerned about their subordinates’ jobs or wellbeing or had little idea of the nature of their roles or the value of the departments for which they were now responsible. These reflections confirm previous findings of the negative impact on organizational members facing possible job loss or more pressurized jobs after a change (e.g. Lawrence and Callan, 2011; Teo et al., 2012).

Given that the process of change required an extra effort for some staff it created greater workload stress, a key factor noted by Robinson and Griffiths (2005) and Armstrong-Stassen (2005) in researching public sector changes. In addition, Armstrong-Stassen found an increase in perceived powerlessness among managers, even those in executive positions. In the current study, some of the comments on powerlessness were made by respondents who were in fairly senior managerial positions, indicating that this level is particularly stressed by losing power. 
The atmosphere of gloom and tension that pervaded their work environment for a lengthy period was particularly difficult for some respondents who were affected by the stress of colleagues, supervisors or subordinates and undermined their acceptance of the change. As Kiefer (2002, p. 45) observes, “expressed and communicated emotions influence group processes, organizational climate, as well as the individual and social construction of change.”

\section{After the change}

For many respondents the initial stages of newly-created roles and structures were very stressful. Part of this was due to the pressure on developing new relationships, vertically and horizontally, partly on learning new skills and understanding - and meeting - contrasting expectations. Two were incensed at the inferior physical accommodation they were relegated to and the literal and figurative marginalization this signified.

While some respondents were pleased that their new roles had delivered both organizational improvements and/or lower personal stress levels, the common refrain was an increase in workload and inadequate resources - the "need to do more with less" - and the relentless pressure that accompanied this dictum. Empirical literature has shown that organizational change often increases workload, that this creates strain for organizational members and that this is particularly prevalent in organizations which have adopted the dogma and practices of New Public Management (Noblet et al., 2006; Teo et al., 2012). One of the senior managers interviewed for the current study admitted that government-driven cost pressures dictated many of the changes that had taken place. Nevertheless, according to a recent comment on ongoing changes for senior nurses in New Zealand, “The DHBs deny that changes are cost driven but we believe it is a major factor in many proposals” (Harry, 2013, p. 39).

\begin{tabular}{|l|l|}
\hline Stressor & Sample quotes \\
\hline Workload & $\begin{array}{l}\text { One week I worked } 60 \text { hours and was just totally exhausted. } \\
\text { The pressure of work is absolutely incredible [...] my workload has effectively doubled. }\end{array}$ \\
\hline
\end{tabular}




\begin{tabular}{|l|l|}
\hline $\begin{array}{l}\text { Continual } \\
\text { uncertainty }\end{array}$ & $\begin{array}{l}\text { You feel threatened and feel you might be next for the chop. } \\
\text { Our jobs might not have been at risk then and they might not be at risk now, but who } \\
\text { the heck knows where it's going to all end? }\end{array}$ \\
\hline $\begin{array}{l}\text { Short-term } \\
\text { contract roles }\end{array}$ & $\begin{array}{l}\text { Facing the fact that you may be out of work and be made redundant is really stressful. } \\
\text { It's a source of stress in that I feel cheated that whenever my job here does finish [...] } \\
\text { you don't get redundancy [pay] with a fixed term contract. }\end{array}$ \\
\hline $\begin{array}{l}\text { Inadequate } \\
\text { resources }\end{array}$ & $\begin{array}{l}\text { When the services are cut back to the bone, we're running on empty. } \\
\text { Every other week there's something new that we need to add to our bow with no extra } \\
\text { finances or people. }\end{array}$ \\
\hline $\begin{array}{l}\text { Inadequate } \\
\text { office location }\end{array}$ & $\begin{array}{l}\text { I was packed to one side. } \\
\text { It was demeaning, it was crap. }\end{array}$ \\
\hline $\begin{array}{l}\text { Relationships: } \\
\text { internal }\end{array}$ & $\begin{array}{l}\text { I have a couple of people in my team who are toxic. One in particular does her level best } \\
\text { to undermine me. } \\
\text { I think we [managers] have a worse relationship with the staff on the floor, because our } \\
\text { focus has changed, it has become very much about pushing people [patients] through as } \\
\text { fast as they can, increased workloads, less staff [...] It's very stressful. }\end{array}$ \\
\hline $\begin{array}{l}\text { Change but no } \\
\text { gain }\end{array}$ & $\begin{array}{l}\text { I am not very happy. Very demotivated. I have given my blood and my guts and it hasn't } \\
\text { made a tap of difference. } \\
\text { They're only tinkering with it [the new system] and most are using half and half, which } \\
\text { is not safe. } \\
\text { All the people with any energy and any enthusiasm went somewhere else. So we lost } \\
\text { them and we kept the deadwood in those management roles. }\end{array}$ \\
\hline
\end{tabular}

Table 3: Causes of stress after the change

Some respondents complained that they had suffered a considerable amount of anxiety, had to re-apply for roles that ultimately changed very little and that the change had not produced better organizational outcomes. Others were bitter that they had to take short-term contract roles which created anxiety for their future prospects but which, so they had been told, also removed the possibility of a redundancy payout. They believed it was unfair on them since some colleagues had simply been redeployed with no loss of benefits. Combined with other stressors, unfairness at work can be seen as a tipping point that leads to burnout, as Maslach and Leiter (2008) found. Studies on distributive injustice (the fairness of outcomes) arising from organizational change are testimony to the stressful effects it can have and other forms of injustice (such as procedural, informational and interpersonal) have negative consequences (Fugate et al., 2012; Smollan, 2012). The possibility of more changes, including further downsizing, was now an additional source of stress. Organizational change in public sector organizations has been shown to be a source of strain when it occurs frequently and when it 
creates uncertainty, job insecurity and fear of a further increase in workload (Paulsen et al., 2005; Rafferty and Griffin, 2006).

\section{Variations of stress through difference phases}

For most of the respondents (22) the transition phase was the most stressful while for the

balance (9) the aftermath was more stressful. Some respondents could not comment on the aftermath of change since they had chosen to focus on a current change which had not yet played out. No respondent indicated that stress before the change was higher than in the next two stages. Bridges (2003) asserts that transitions are particularly painful due to the uncertainty of outcomes and the heavier workload, findings apparent in several empirical studies (e.g. Armstrong-Stassen, 2005; Paulsen et al., 2005).

\section{Conclusions, limitations and implications for research and practice}

For most respondents change proved to be stressful. This is unsurprising, given that volunteers were requested for a project explicitly titled Stress and Organizational Change. For many it was a drawn out process, at times poorly managed, that was the prime source of stress while for others it was the negative outcomes, for themselves and others, particularly heavier workloads, redundancies of unwelcome working conditions.

While the transition phase was most stressful for the majority of the respondents, there are a number of limitations to the study. Firstly, a neat separation of phases of change for some proved elusive. Rumours of change or more formal notifications often took place a long time before an official announcement from the top. In addition, the last phase of the implementation phase had not yet been reached by some while for others it could be construed as the initial stage of the new situation, which was particularly stressful for a while (sometimes up to a year) but abated as respondents became accustomed to the new situation and the skills and 
relationships involved. Some respondents reported that other changes occurred concurrently or after the change being discussed and that it was sometimes difficult to isolate the stressors of each change. Longitudinal quantitative studies are useful ways of tracking occupational stress levels through different phases of change and prior research (with the exception of the study by Paulsen et al. (2005) does not appear to have used an instrument with the same items over three phases of change.

Secondly, while most participants spoke of changes that occurred within the last four years others went further back. Since memory fades Levine et al. (2012) argue that people tend to reconstruct events from their current mindsets and cannot recall all the shifting emotions and triggering experiences. There is another view that despite the weaknesses of memory emotion may in some cases enhance the recall of events (Talarico et al., 2004). In addition, common method variance may bedevil quantitative studies (Podsakoff et al., 2003). These two issues reinforce the notion that longitudinal studies, quantitative or qualitative, would be useful ways of tracking stress prior to change and at different periods thereafter, where memory spans are much shorter.

Thirdly, in the current study interviews were conducted with a range of respondents in one New Zealand health authority. Further research could explore the stress of different types of public sector changes as they unfold in different countries and compare these to changes in other sectors. Changes in public sector organizations are driven by different national and regional factors and comparative studies are a rich vein of material to mine.

From a practitioner perspective, leaders in the health sector and other areas of government need to be aware of how organizational changes, particularly large-scale restructures, undermine the wellbeing and performance of many employees. Anticipating how change may stress employees is necessary for managers at all levels. The provision of welldesigned training courses, in organizational change and stress management, will also help to 
equip them with the insights and skills to mitigate some of the damaging effects of stress. The present study showed staff unhappiness with some organizational processes where they were not consulted or informed, and where they suffered from uncertainty, heavy workloads and inadequate support. While the imperatives of the (no longer) "New” Public Management will continue to pressurize its organizations’ leaders (Kuipers et al., 2013, they can exercise some discretion in planning and implementing change. More constructive organizational cultures and better management practices can attenuate some of the ill-effects of change.

In conclusion, this study has contributed to the literatures on organizational change, stress and public sector management, by revealing varying causes and levels of stress as change processes move through different phases.

\section{References}

Allen, J., Jimmieson, N.J., Bordia, P. and Irmer, B.E. (2007), "Uncertainty during organizational change: managing perceptions through communication”, Journal of Change Management, Vol. 7 No. 2, pp. 187-220.

Armstrong-Stassen, M. (2005), “Coping with downsizing: a comparison of executive-level and middle managers. International Journal of Stress Management, Vol. 12 No. 2, pp. 117141.

Bakker, A.B. and Demerouti, E. (2007), “The Job Demands-Resources model: state of the art”, Journal of Managerial Psychology, Vol. 22 No. 3, pp. 309-328.

Baltzer, M., Westerlund, H., Backhans, M. and Melinder, K. (2011), "Involvement and structure: a qualitative study of organizational change and sickness absence among women in the public sector in Sweden”, BMC Public Health, Vol. 11 No. 4, pp. 318334. 
Bamberger, S.G., Vinding, A.L., Larsen, A. Nielsen, P., Fonager, K., Nielsen, R.N; Ryom, R. and Omland, O. (2012), “Impact of organizational change on mental health: a systematic review”, Occupational and Environmental Medicine, Vol. 69, pp. 592-598.

Bridges, W. (2003). Managing Transitions: Making the Most of Change ( ${ }^{\text {nd }}$ ed.), Perseus Publishing , Cambridge, MA.

Bryant, M. (2006), “Talking about change: understanding employee responses through qualitative research”, Management Decision, Vol. 44 No. 2, pp. 46-58.

Campbell-jamison, F., Worrall, F. and Cooper, C. (2001), “Downsizing in Britain and its effects on survivors and their organizations”, Anxiety, Stress and Coping, Vol. 14, pp. 35-58.

Clair, J.A. and Dufresne, R.L. (2004), "Playing the grim reaper: how employees experience carrying out a downsizing", Human Relations, Vol. 57 No. 12, pp. 1597-1625.

Devine, K., Reay, T., Stainton, L. and Collins-Nakai, R. (2003), “Downsizing: better a victim than a survivor?”, Human Resource Management, Vol. 42 No. 2, pp. 109-124.

Diefenbach, T. (2009), “New public management in public sector organizations: the dark sides of managerialistic ‘enlightenment'”, Public Administration, Vol. 87 No. 4, pp. 892-909.

Driver, M. (2009), “From loss to lack: stories of organizational change as encounters with failed fantasies of self, work and organization”, Organization, Vol. 16 No. 3, pp. 353-369.

Faragher, E.B., Cooper, C.L. and Cartwright, S. (2004), “A shortened stress evaluation tool (ASSET)”, Stress and Health, Vol. 20 No. 4, pp. 189-201.

Fugate, M., Prussia, G.E. and Kinicki, A.J. (2012), "Managing employee withdrawal during organizational change: the role of threat appraisal”, Journal of Management, Vol. 38 No. 3, pp. 890-914.

Gandolfi, F. (2009), “Executing downsizing: the experience of executioners”, Contemporary Management Research, Vol. 5 No. 2, pp. 185-200. 
Gauld, R. (Ed) (2003), Continuity amid Chaos: Health Care Management and Delivery in New Zealand, Otago University Press, Dunedin.

Harry, L. (2013), “DHBs’ processes must be robust”, Kai Tiaki Nursing New Zealand, Vol. 18 No. 11, p. 9 .

Health and Safety Executive, Working Together to Reduce Stress at Work: A Guide for Employees, available at http://www.hse.gov.uk/pubns/indg424.pdf. (accessed 14 February 2014).

Hobfoll, S.E. (1998), Stress, Culture and the Community, Plenum Press, New York.

Isabella, L.A. (1990), “Evolving interpretations as change unfolds: how managers construe key organizational events”, Academy of Management Journal, Vol. 33 No. 1, pp. 7-41.

Karasek, R.A. (2004), “An analysis of 19 international case studies of stress prevention through work reorganization using the demand/control model”, Bulletin of Science, Technology and Society, Vol. 24 No. 5, pp. 446-456.

Karasek, R., Brisson, C., Kawakami, N., Houtman, I., Bongers, P. and Amick, B. (1998), “The Job Content Questionnaire (JCQ): an instrument for internationally comparative assessments of psychosocial job characteristics”, Journal of Occupational Health Psychology, Vol. 3 No. 4, pp. 322-355.

Kiefer, T. (2002), “Understanding the emotional experience of organizational change: evidence from a merger”, Advances in Developing Human Resources, Vol. 4 No. 1, pp. 39-61.

Kuipers, B.S., Higgs, M.J., Kickert, W.J.M., Tummers, L.G., Grandia, J. and Voet, J. (2013), "The management of change in public organisations: a literature review", Public Administration, 1-45 (online before print).

Lawrence, S. and Callan, V. (2011), "The role of social support in coping during the anticipatory stage of organizational change: a test of an integrative model”, British Journal of Management, Vol. 22 No. 4, pp. 567-585. 
Lazarus, R. S. (1993), “From psychological stress to the emotions: a history of changing outlooks”, Annual Review of Psychology, Vol. 4, pp. 1-21.

Levine, L.J., Schmidt, S., Kang, H.S. and Tinti, C. (2012), “Remembering the silver lining: reappraisal and positive bias in memory for emotion”, Cognition and Emotion, Vol. 26 No. 5, pp. 871-884.

Mak, A.S. and Mueller, J. (2000), “Job insecurity, coping resources and personality dispositions in occupational strain”, Work \& Stress: An International Journal of Work, Health \& Organisations, Vol. 14 No. 4, pp. 312-328.

Maslach, C. and Leiter, M.P. (2008), “Early predictors of job burnout and engagement”, Journal of Applied Psychology, Vol. 93 No. 3, pp. 498-512.

Oreg, S., Michel, A. and By, R.T. (2013), “Introduction”, in Oreg, S., Michel, A. and By, R.T. (Eds), The Psychology of Organizational Change: Viewing Change from the Employee’s Perspective, Cambridge University Press, Cambridge, UK, pp. 3-14.

Noblet, A., Rodwell, J. and McWilliams, J. (2006), “Organisational change in the public sector: augmenting the demand control model to predict employee outcomes under New Public Management”, Work \& Stress, Vol. 20, No. 4, pp. 335-352.

Parris, M.A. and Vickers, M.H. (2010), “Look at him...he’s failing”: male executives’ experiences of redundancy”, Employee Responsibilities and Rights Journal, Vol. 22 No. 4, pp. 345-357.

Paulsen, N., Callan, V.J., Grice, T.A., Rooney, D., Gallois, C., Jones, E., Jimmieson, N.L. and Bordia, P. (2005), “Job uncertainty and personal control during downsizing: a comparison of survivors and victims”, Human Relations, Vol. 58 No. 4, pp. 463-496.

Pick, F., Teo, S. and Yeung, M. (2011), “Friend or foe? New managerialism and technical, administrative and clerical support staff in Australian universities”, Higher Education Quarterly, Vol. 66 No. 1, pp. 3-23. 
Podsakoff, P.M., MacKenzie, S.P., Lee, J.-Y. and Podsakoff, N.P. (2003), “Common method biases in behavioral research: a critical review of the literature and recommended remedies”, Journal of Applied Psychology, Vol. 88 No. 5, pp. 879-903.

Rafferty, A.E. and Griffin, M. (2006), "Perceptions of organizational change: a stress and coping perspective”, Journal of Applied Psychology, Vol. 91 No. 5, pp. 1154-1162.

Riolli, L. and Savicki, V. (2006), “Impact of fairness, leadership, and coping on strain, burnout and turnover in organizational change”, International Journal of Stress Management, Vol. 13 No. 3, pp. 351-377.

Robinson, O. and Griffiths, A. (2005), “Coping with the stress of transformational change in a government department”, The Journal of Applied Behavioral Science, Vol. 41. No. 2, pp. 204-221.

Sasvik, P.O., Tvedt, S.D., Nytrø, K., Andersen, G.A., Andersen, T.K., Buvik, M.P. and Torvatn, H. (2007), “Developing criteria for healthy organizational change”, Work \& Stress, Vol. 21 No. 3, pp. 243-263.

Smollan, R.K. (2012), "Emotional responses to the injustice of organizational change: a qualitative study”, in Ashkanasy, N.M., Hartel, C.E.J. and Zerbe, W.J. (Eds), Research on Emotion in Organizations, Vol. 8, Emerald Insight, Bingley, UK, pp. 175-202.

Smollan, R.K. and Sayers, J. G. (2009), “Organizational culture, organizational change and emotions: a qualitative study”, Journal of Change Management, Vol. 9 No. 4, pp. 435457.

Talarico, J.M., Labar, K. and Rubin, D.C. (2004), "Emotional intensity predicts autobiographical memory”, Memory and Cognition, Vol. 32 No. 7, pp. 1118-1132.

Teo, S.T.T., Yeung, M. and Chang, E. (2012), “Administrative stressors and nursing job outcomes in Australian public and non-profit healthcare organisations”, Journal of Clinical Nursing, Vol. 21 No. 9-10, pp. 1443-1452. 